$\begin{array}{ll}\text { Research Square } & \begin{array}{l}\text { Preprints are preliminary reports that have not undergone peer review. } \\ \text { They should not be considered conclusive, used to inform clinical practice, } \\ \text { or referenced by the media as validated information. }\end{array}\end{array}$

\title{
A Combined Index of Waist Circumference and Muscle Quality is Associated with Accumulation of Cardiovascular Disease Risk Factors in Obese Patients: A Cross-sectional Study
}

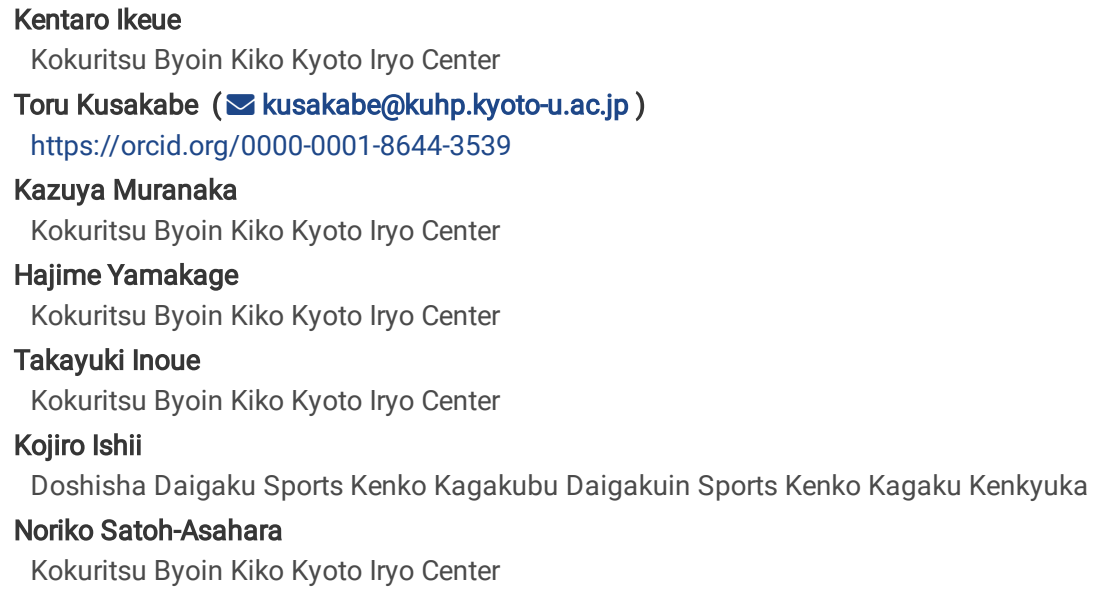




\section{Abstract}

Background: Aging individuals are prone to sarcopenic obesity (SO). SO is associated with higher risks of low physical function, metabolic diseases, cardiovascular disease (CVD), and mortality. Worldwide diagnostic criteria for SO and its cutoff values have not yet been established. In this study, from among obesity- and sarcopenia-evaluated indices, we determined a combined index most associated with the accumulation of CVD risk factors in obese patients.

Methods: In this cross-sectional study, we evaluated body composition using a multifrequency bioelectrical impedance analysis device and measured handgrip strength in 188 obese patients (73 men and 115 women). We selected each index most associated with the accumulation of CVD risk factors among obesity- (body mass index, percentage body fat, or waist circumference [WC]) and sarcopenia-evaluated indices (skeletal mass index, handgrip strength, or muscle quantity [MQ]), respectively. We then classified obese patients into four groups (group C, control; group 0, obesity alone; group S, sarcopenia alone; and group SO, sarcopenic obesity) using the two selected indices with each median value and compared the CVD risk score, the number of concomitant CVD risk factors, among the four groups.

Results: Based on the dichotomous comparison, WC and MQ were selected as the indices most associated with CVD risk factor accumulation. The CVD risk score was significantly higher in groups $S$ and $S O$ as compared with group C $(1.94 \pm 0.80,1.95 \pm 0.91$ vs. $1.41 \pm 0.84$, all $p<0.05)$. Odds ratios for CVD risk scores $\geq 2$ were significantly higher in groups $\mathrm{S}, \mathrm{O}$, and SO compared with group C (4.78 [95\% confidence interval $\{\mathrm{Cl}\} 1.79-12.81], p=0.002 ; 3.28$ [95\% Cl 1.377.88 ], $p=0.008 ; 3.92$ [95\% $\mathrm{Cl} 1.74-8.81], p=0.001$; respectively). Furthermore, odds ratios for $\mathrm{CVD}$ risk scores $=3$ were significantly higher only in group SO compared with group C (4.29 [95\% Cl 1.49-12.33], $p=0.007)$.

Conclusion: In obese patients, WC and MQ were most associated with the accumulation of CVD risk factors, respectively. Furthermore, classification using the combined index of WC and MQ reflects the accumulation of CVD risk factors in obese patients, regardless sex and age.

\section{Background}

The aging of the population is progressing on a global scale, as life expectancy increases and fertility rates decline. The World Health Organization predicts that the worldwide proportion of elderly individuals aged 65 and older will double between the years 2000 and 2050, from the current $6.9 \%$ to $16.4 \%$ [1]. Aging increases the prevalence of common diseases such as cancers, diabetes, and cardiovascular disease (CVD).

Aging induces changes in body composition, such as an increase in body fat and a decline in skeletal muscle [2, 3]. Body fat increases until the seventh decade of life and decreases thereafter [4]. It has been reported that most of the body fat increase with aging is due to the increase in visceral fat [5]. On the other hand, skeletal muscle mass and strength reach their maximum amount at young adulthood (up to $\sim 40$ years of age) and then decline by several percent each year [6].

Obesity, defined as an increase in adipose tissue, predisposes to obesity-associated diseases such as hypertension, type 2 diabetes, and dyslipidemia, and their accumulation leads to CVD [7]. In particular, excess visceral fat causes low-grade systemic chronic inflammation and has a greater impact on metabolic abnormalities, CVD, and mortality than subcutaneous fat does [8, 9].

Sarcopenia is the loss of muscle mass and strength or physical function that occurs naturally with aging $[4,6,10]$. Probable sarcopenia is identified by low muscle strength, and the diagnosis of sarcopenia is confirmed by the additional documentation of low muscle quantity or quality [6]. According to a recent systematic review and meta-analysis, the worldwide prevalence of sarcopenia is $10 \%$ (95\% confidence interval [Cl] $8-12 \%)$ in men and $10 \%(95 \% \mathrm{Cl} 8-13 \%$ ) in women, respectively [11]. It has been reported that sarcopenia is associated with a number of different outcomes such as falls and fractures [12-14], disability $[12,15]$, metabolic syndrome [16], CVD [17, 18], and mortality $[12,19]$.

Sarcopenic obesity (SO) was first described by Heber et al as the co-presence of sarcopenia and obesity [20]. Sarcopenia and obesity have some common pathophysiological mechanisms, including increased inflammatory cytokines, oxidative stress, insulin resistance, hormonal changes, and decreased physical activity [2]. Furthermore, a vicious cycle may exist between sarcopenia and obesity; that is, sarcopenia reduces physical activity, leading to an increase in the risk of obesity, and excess accumulation of visceral fat induces inflammation, leading to the development of sarcopenia. Therefore, it is feared that sarcopenic obesity will increase with aging.

Elderly individuals with SO have higher risks of low physical function [21, 22], metabolic diseases [23, 24], CVD [25-27], and mortality [25, 28]. These clinical problems in SO are much more severe than in sarcopenia or obesity alone. In the diagnosis of So, sarcopenia and obesity have been diagnosed separately as two distinct categories. However, worldwide diagnostic criteria for SO and its cutoff values have not yet been established [29, 30]. One probable reason for the difficulty in establishing diagnostic criteria for $\mathrm{SO}$ is that there are multiple indices for evaluating sarcopenia and obesity. In addition, the diagnostic criteria for SO needs to be considered for each of the different subjects and clinical outcomes.

In this study, to establish a diagnostic method for SO, we examined a combined index most associated with the accumulation of CVD risk factors in obese patients among obesity-evaluated indices, body mass index (BMI), percentage body fat (PBF), or waist circumference (WC), and the sarcopenia-evaluated indices, skeletal muscle index (SMI), handgrip strength (HGS), or muscle quality (MQ).

\section{Methods Study participants}


This cross-sectional study included obese outpatients who regularly visited the Diabetes Center at the National Hospital Organization Kyoto Medical Center between January 2019 and July 2019. The diagnosis of obesity was based on the standards of the Japan Obesity Society, BMI $\geq 25 \mathrm{~kg} / \mathrm{m}^{2}$ [31]. We excluded participants with incomplete data, implantation of a cardiac pacemaker, and cancer from the study. This study was approved by the Ethics Committee for

Human Research at National Hospital Organization Kyoto Medical Center (approval No. 19-083) and was conducted in accordance with the principles of the Declaration of Helsinki and the ethical guidelines for medical and health research involving human subjects.

\section{Clinical examination}

We measured height and body weight in increments of $0.1 \mathrm{~cm}$ and $0.1 \mathrm{~kg}$, respectively. BMI was calculated as the body weight (kg) divided by the squared height $\left(\mathrm{m}^{2}\right)$. WC was measured at the umbilical level in a standing position. HGS was measured twice for each hand using the Smedley grip force system (Grip-D, Takei Equipment Company, Tokyo, Japan) in a standing position, and the maximum value was included in the analyses. The appendicular skeletal muscle mass (ASM) and PBF were measured using a multifrequency bioelectrical impedance analysis device (MC-780A-N, TANITA, Tokyo, Japan). A previous validation study demonstrated that body composition measured using this device was highly correlated with measurements obtained from of dual-energy $X$ ray absorptiometry [32]. SMI was calculated as the ASM ( $\mathrm{kg})$ divided by the squared height $\left(\mathrm{m}^{2}\right)$. In this study, MQ was calculated as the HGS (kg) divided by muscle mass of the upper limbs $(\mathrm{kg})$ according to previous reports [33-35]. Systolic and diastolic blood pressure was measured with an automatic electrical sphygmomanometer (BP-203RVऋ; Fukuda Colin, Kyoto, Japan). Blood was taken from the antecubital vein in the morning after an overnight fast, and we determined fasting plasma glucose, hemoglobin A1c (HbA1c), triglycerides (TG), high-density lipoprotein cholesterol (HDL-C), and low-density lipoprotein cholesterol (LDL-C).

\section{Diagnosis of sarcopenia}

Sarcopenia was diagnosed by low SMI and weak HGS [6]. The cutoff values for low SMI were $<7.0 \mathrm{~kg} / \mathrm{m}^{2}$ for men and $<5.7 \mathrm{~kg} / \mathrm{m}^{2}$ for women and those for weak HGS were $<28 \mathrm{~kg}$ for men and $<18 \mathrm{~kg}$ for women, respectively [10].

\section{Diagnosis of hypertension, diabetes, and dyslipidemia}

The diagnosis of hypertension, diabetes, and dyslipidemia was based on the criteria of each academic society; hypertension was defined as systolic blood pressure $\geq 140 \mathrm{mmHg}$ and/or diastolic blood pressure $\geq 90 \mathrm{mmHg}$ or taking medications for hypertension [36]; diabetes was defined by fasting plasma glucose $\geq 126 \mathrm{mg} / \mathrm{dL}$, and/or random plasma glucose $\geq 200 \mathrm{mg} / \mathrm{dL}$, and/or HbA1c (National Glycohemoglobin Standardization Program) $\geq 6.5 \%$, or taking medications for diabetes [37]; dyslipidemia was defined by LDL-C $\geq 140 \mathrm{mg} / \mathrm{dL}$, and/or HDL-C $<40 \mathrm{mg} / \mathrm{dL}$, and/or TG $\geq 150 \mathrm{mg} / \mathrm{dL}$, or taking medications for dyslipidemia [38].

\section{Definition of CVD risk score}

In this study, the CVD risk score was defined as the number of concomitant CVD risk factors (hypertension, diabetes, and dyslipidemia; 0-3 points), referring to a previous report [9].

\section{Classification of obese patients using each obesity- and sarcopenia-evaluated index}

As shown in Figure 1, obese patients were classified into four groups using each obesity-and sarcopenia-evaluated index with the median value: group C, control (low obesity-evaluated index and high sarcopenia-evaluated index); group S, sarcopenia alone (low obesity-evaluated index and low sarcopeniaevaluated index); group 0, obesity alone (high obesity-evaluated index and high sarcopenia-evaluated index); and group SO, sarcopenic obesity (high obesityevaluated index and low sarcopenia-evaluated index).

\section{Statistical analysis}

We performed statistical analyses using SPSS (version 25; IBM Corp, Armonk, NY, USA). Data are presented as mean \pm standard deviation, median (interquartile range), or frequency percentage. In all cases, a probability $(p)$ value of $<0.05$ was considered statistically significant.

Obese patients were dichotomized by the median value in each obesity- and sarcopenia-evaluated index. Those above the median value were classified as "high" and those below as "low." We conducted an analysis of covariance (ANCOVA) to compare the CVD risk scores between the low and high groups in each obesity-evaluated index (BMI, PBF, or WC) and sarcopenia-evaluated index (SMI, HGS, or MQ). The ANCOVA was constructed as follows: model 1 was unadjusted, model 2 was adjusted for sex, and model 3 was further adjusted for age. We conducted analysis of variance followed by Tukey's test or KruskalWallis test followed by Bonferroni correction for continuous variables and chi-square test for categorical variables to compare the characteristics of the four groups (group C, group S, group O, and group SO). We used multiple logistic regression analysis to determine odds ratios (ORs) and $95 \%$ Cls for each CVD risk score $(\geq 1, \geq 2$, and $=3)$ as compared with group $C$, after adjusting for sex and age.

\section{Results}




\section{Clinical characteristics of the study participants}

As shown in Figure 2, 196 patients (76 men and 120 women) were enrolled in this study. Six patients with incomplete data, one patient with a cardiac pacemaker, and one patient undergoing treatment for cancer were excluded. Finally, 188 obese patients (73 men and 115 women) were included in the study population.

Table 1 summarizes the clinical characteristics of the obese patients. Elderly patients aged 65 years and older included 22 men (30.1\%) and 40 women (34.8\%), respectively. As for the obesity-evaluated indices, BMls were $30.6(27.3-34.2) \mathrm{kg} / \mathrm{m}^{2}$ in men and $31.8(28.8-36.3) \mathrm{kg} / \mathrm{m}^{2} \mathrm{in}$ women, PBF values were $34.3 \% \pm 7.2 \%$ in men and $48.5 \% \pm 8.0 \%$ in women, and WCs were $103.0(98.5-111.0) \mathrm{cm}$ in men and $102.0(95.0-111.0) \mathrm{cm}$ in women, respectively. There were 71 men (97.3\%) with an abdominal circumference of $\geq 85 \mathrm{~cm}$ and 102 women (88.7\%) with an abdominal circumference of $\geq 90 \mathrm{~cm}$, suggesting that the participants had substantial visceral fat accumulation. On the other hand, as for the sarcopenia-evaluated indices, SMls were $8.94 \pm 1.04 \mathrm{~kg} / \mathrm{m}^{2} \mathrm{in} \mathrm{men} \mathrm{and}$ $7.47 \pm 0.83 \mathrm{~kg} / \mathrm{m}^{2}$ in women, HGS values were $39.6 \pm 7.4 \mathrm{~kg}$ in men and $23.7 \pm 4.9 \mathrm{~kg}$ in women, and MQs were $6.59 \pm 1.12 \mathrm{~kg} / \mathrm{kg}$ in men and $6.52 \pm 1.18$ $\mathrm{kg} / \mathrm{kg}$ in women, respectively. Low SMI was observed in 3 men (4.1\%) and weak HGS was noted in 5 men (6.8\%) and 14 women (12.2\%), respectively. However, sarcopenia was diagnosed in only one male (1.4\%). The prevalence of hypertension, diabetes, and dyslipidemia was high; therefore, patients had a high CVD risk score $(1.92 \pm 0.86$ in men and $1.65 \pm 0.90$ in women).

\section{Obesity-evaluated index most associated with the accumulation of CVD risk factors}

For the obesity-evaluated indices, the median BMI was $30.6 \mathrm{~kg} / \mathrm{m}^{2}$ in men and $31.8 \mathrm{~kg} / \mathrm{m}^{2}$ in women, the median PBF were $34.1 \%$ in men and $47.7 \%$ in women, and the median WC was $103.0 \mathrm{~cm}$ in men and $102.0 \mathrm{~cm}$ in women, respectively. Table 2A shows the comparisons of CVD risk scores between the low and high groups in each obesity-evaluated index. The CVD risk score was significantly higher in the high group as compared with the low group only for WC (1.62 [95\% Cl 1.43-1.80] vs. 1.88 [95\% Cl 1.70-2.05], $p<0.05$; model 1). Furthermore, the association persisted even after adjusting for sex (1.61 [95\% $\mathrm{Cl} 1.43-$ $1.80]$ vs. 1.88 [95\% $\mathrm{Cl} 1.71-2.06], p<0.05 ;$ model 2$)$ and for sex and age (1.58 [95\% Cl 1.40-1.76] vs. 1.91 [95\% $\mathrm{Cl} 1.74-2.08], p<0.01 ;$ model 3$)$.

\section{Sarcopenia-evaluated index most associated with accumulation of CVD risk factors}

For the sarcopenia-evaluated indices, the median SMI was $8.98 \mathrm{~kg} / \mathrm{m}^{2}$ in men and $7.37 \mathrm{~kg} / \mathrm{m}^{2}$ in women, the median HGS were $40.6 \mathrm{~kg}$ in men and $23.5 \mathrm{~kg}$ in women, and the median MQ was $6.63 \mathrm{~kg} / \mathrm{kg}$ in men and $6.58 \mathrm{~kg} / \mathrm{kg}$ in women, respectively. Table 2B shows the comparisons of CVD risk scores between the low and high groups in each sarcopenia-evaluated index. The CVD risk score was significantly higher in the low group compared with the high group only for MQ (1.95 [95\% Cl 1.77-2.13] vs. 1.57 [95\% Cl 1.40-1.75], $p<0.01$; model 1). Furthermore, the association persisted even after adjusting for sex (1.95 [95\% $\mathrm{Cl}$ 1.77-2.12] vs. 1.57 [95\% Cl 1.39-1.74], $p<0.01$; model 2 ) and for sex and age (1.93 [95\% Cl 1.76-2.10] vs. 1.58 [95\% Cl 1.41-1.75], $p<0.01 ;$ model 3).

\section{Clinical characteristics of the obese patients classified by a combined index of WC and MQ}

Based on the above results, we selected WC and MQ as the indices most associated with accumulation of CVD risk factors, respectively. Then, we classified obese patients into four groups using WC and MQ with each median value (Figure 1). By this classification, group S had significantly lower MQ compared with group C (5.49 \pm 0.85 vs. $7.50 \pm 0.71 \mathrm{~kg} / \mathrm{kg}, p<0.05)$, group O had significantly higher WC compared with group C (111.0 [106.3-118.3] vs. 95.0 [89.8-99.0] cm, $p<0.05)$, and group SO had significantly lower MQ and higher WC compared with group C $(5.71 \pm 0.72 \mathrm{vs.} 7.50 \pm 0.71 \mathrm{~kg} / \mathrm{kg}, p<0.05 ; 110.5$ [106.8-121.5] vs. 95.0 [89.8-99.0] cm, $p<0.05$, respectively; Table 3). As for other obesity- and sarcopenia-evaluated indices, both BMI and PBF were also significantly higher in group $\mathrm{O}$ and group SO compared with group C (all $p<0.05$ ), and HGS was also lower in group S and group SO compared with group C (all $p<0.05$; Table 3 ). Interestingly, in contrast to $\mathrm{MQ}$, the $\mathrm{SMI}$ in group SO was significantly higher than that in group $\mathrm{C}\left(8.32 \pm 1.27 \mathrm{vs} .7 .82 \pm 1.03 \mathrm{~kg} / \mathrm{m}^{2}, p<0.05\right)$.

Although there was no significant difference in the prevalence of hypertension and dyslipidemia among the four groups, that of diabetes was significantly higher in group S, group 0 , and group SO compared with group C (48.6, 41.5, 44.8 vs. $16.7 \%$, all $p<0.05$; Table 3$)$. The CVD risk score was also significantly higher in group $S$ and group SO compared with group C $(1.94 \pm 0.80,1.95 \pm 0.91$ vs. $1.41 \pm 0.84$, all $p<0.05$; Table 3$)$.

\section{ORs for accumulation of CVD risk factors in obese patients classified by a combined index of WC and MQ}

Finally, we investigated the effect of a combined index of WC and MQ on the CVD risk score (Figure 3). All ORs were adjusted for sex and age. We found no difference in ORs for CVD risk scores $\geq 1$ among the four groups. However, ORs for CVD risk scores $\geq 2$ were significantly higher in group $S$, group 0 , and group SO compared with group C (4.78 [95\% Cl 1.79-12.81], $p=0.002 ; 3.28$ [95\% Cl 1.37-7.88], $p=0.008 ; 3.92$ [95\% Cl 1.74-8.81], $p=0.001 ;$ respectively). Furthermore, ORs for CVD risk scores $=3$ were significantly higher only in group SO compared with group C (4.29 [95\% Cl 1.49-12.33], $p=0.007)$.

\section{Discussion}

To the best of our knowledge, this is the first study to determine a combined index associated with the accumulation of CVD risk factors in obese patients among each of the obesity- (BMI, PBF, or WC) and sarcopenia-evaluated indices (SMI, HGS, or MQ), respectively. Among obese patients, sarcopenia was 
diagnosed in only one man (1.4\%). This result is consistent with previous studies reporting that few obese individuals diagnosed with high BMI meet the conventional diagnostic criteria for sarcopenia $[6,10,39,40]$. However, the prevalence of hypertension, diabetes, and dyslipidemia in these patients was high (Table 1), indicating that they are at a high risk for CVD. Therefore, we attempted to establish a diagnostic method for SO that reflects CVD risk. In this study, we provided evidence that classification using the combined index of WC and MQ reflects the accumulation of CVD risk factors in obese patients, regardless sex and age.

Many indices have been proposed for evaluating obesity. However, controversy remains on the obesity-evaluated index that best reflects the accumulation of CVD risk factors [41]. In this study, WC was most highly associated with the accumulation of CVD risk factors as compared with BMI and PBF, regardless of sex and age (Table 2A). BMI has been widely used to determine the prevalence of obesity and various risks in populations. In addition, PBF is often used as a criterion for evaluating the magnitude of accumulation of adipose tissue. However, in recent years, the indices of abdominal obesity, mainly WC, have been shown to be more closely related to CVD and mortality than BMI and PBF are [42, 43], which is consistent with the findings of our study.

Many indices have been proposed to evaluate sarcopenia, including muscle mass, muscle strength, physical performance, and MQ, but it is also unclear which sarcopenia-evaluated index best reflects CVD risk accumulation. Cao et al reported that in patients with metabolic syndrome, low SMI may be an independent risk factor for atherosclerosis [44]. In addition, low HGS has been reported to be associated with coronary artery calcification, CVD, and all-cause mortality [4547] Our study demonstrated that MQ was most associated with the accumulation of CVD risk factors compared with SMI and HGS, regardless of sex and age (Table 2B). MQ was reported to be negatively associated with insulin resistance after adjusting for age, body fat, highly sensitive C-reactive protein levels, and physical activity level in adult obese women [48] and further that insulin resistance contributes to the development of atherosclerosis [49, 50], findings that are consistent with our results.

In this study, HGS was lower in group SO compared with group C $\left(27.9 \pm 9.0 \mathrm{vs.} 33.0 \pm 9.7 \mathrm{~kg} / \mathrm{m}^{2}, p<0.05\right)$, whereas SMI was significantly higher in group SO compared with group C ( $8.32 \pm 1.27$ vs. $7.82 \pm 1.03 \mathrm{~kg} / \mathrm{m}^{2}, p<0.05$; Table 3$)$. Therefore, MQ calculated as the HGS (kg) divided by the muscle mass of the upper limbs was significantly lower in group SO compared with group C (5.71 $\pm 0.72 \mathrm{vs.} 7.50 \pm 0.71 \mathrm{~kg} / \mathrm{kg}, p<0.05$; Table 3). Mesinovic et al reported that overweight and obese older adults with metabolic syndrome have larger muscle size but poor MQ [51]. The lower MQ in group SO might be attributed to increased fat accumulation in the muscles [52,53]; however, in this study, we did not measure MQ with imaging analysis, such as ultrasonography or computed tomography. Recently, the usefulness of phase angle as an indicator for MQ has been suggested [6,54], and further studies on the increased fat accumulation in muscles are required in the future.

The combined index of WC and MQ was well associated with the accumulation of CVD risk factors in obese patients (Figure 3). To the best of our knowledge, there have been no reports on the diagnostic method for SO using a combined index of WC and MQ. Murai et al reported that patients with type 2 diabetes who had both visceral fat accumulation and low MQ were more affected with CVD [34]. The effectiveness of the combined index of WC and MQ as a relevant indicator of accumulation of CVD risk factors in obese patients requires further investigation.

The use of multiple medications per day is common with aging. Many drugs taken regularly for diseases may interact with some mechanisms that can alter the balance between protein synthesis and degradation [55], and researchers have reported that polypharmacy is associated with sarcopenia [56]. In this study, diuretics and biguanide (BG) were used significantly more often in group SO compared with group $\mathrm{S}$ and group $\mathrm{C}$, respectively $(p<0.05, p<0.05$; Supplementary Table S1). The use of diuretics, particularly loop diuretics, has been suggested as a risk factor of sarcopenia [57]. On the other hand, BG improves insulin resistance and may inhibit the progression of sarcopenia [55]. Unfortunately, we did not assess insulin resistance in this study, but it has been reported that patients with SO are in an insulin-resistant state $[2,4]$. It is likely that BG was provided for insulin resistance in group SO in this study. The effects of $B G$ on muscle remain to be elucidated.

The present study had several limitations that warrant mention. First, our study used a cross-sectional design. Thus, we could investigate only the associations between the combined index of WC and MQ and the accumulation of CVD risk factors. Second, because of the hospital-based design of the study, there may be bias among the study participants, which could limit the generalization of the study results. Third, the cutoff values for both WC and MQ were not clear. However, we were able to diagnose SO using the median of WC and MQ indices as cutoff values, which reflected well the accumulation of CVD risk factors. To resolve these limitations, larger cohort and prospective studies including various populations are needed in the future.

In conclusion, our study demonstrated that the obesity-evaluated index, WC, and the sarcopenia-evaluated index, MQ, were most closely associated with the accumulation of CVD risk factors in obese patients, respectively. Furthermore, classification by the combined index of WC and MQ reflects the accumulation of CVD risk factors in obese patients, regardless of sex and age.

\section{Abbreviations}

ANCOVA: analysis of covariance; ASM: appendicular skeletal muscle mass; BG, biguanide; BMI: body mass index; Cl: confidence interval; CVD: cardiovascular disease; HbA1c, hemoglobin A1c; HDL-C: high-density lipoprotein cholesterol; HGS: handgrip strength; LDL-C: low-density lipoprotein cholesterol; MQ: muscle quality; OR: odds ratio; PBF: percentage body fat; SMI: skeletal muscle mass index; SO: sarcopenic obesity; TG: triglycerides; WC: waist circumference.

\section{Declarations}

\section{Ethics approval and consent to participate}

This study was approved by the ethics committee for human research at Kyoto Medical Center (approval No. 19-083). All subjects provided written informed consent. 


\section{Consent for publication}

Not applicable.

\section{Availability of data and materials}

The data sets used and/or analyzed during the current study are available from the corresponding author on reasonable request.

\section{Competing interests}

All authors of this manuscript declare no conflicts of interest.

\section{Funding}

This study was supported in part by a grant from the National Hospital Organization for collaborative clinical research to T.K. (H30-NHO-03, R3-NHO-01), Grant-in-Aid for Scientific Research (C) to T.K. (JSPS KAKENHI grant No. 21K11691) and Scientific Research (B) to N.S-A. (JSPS KAKENHI grant No. $18 H 02737$ and 21H02835), and Grant-in-Aid for Exploratory Research to N.S.-A. (18K19769) from Japan Society for the Promotion of Science. This study was also supported in part by a grant from Smoking Research Foundation to T.K. (2020T007) and N.S.-A. (2019T004). The funders played no role in the study design, data collection and analysis, decision to publish, or preparation of the manuscript.

\section{Authors' contributions}

K.I. acquired and analyzed the data and wrote the manuscript. T.K. conceived the study and wrote the manuscript. K.M., H.Y., T.I., K.I., and N.S.-A. reviewed the manuscript. All authors read and approved the final manuscript.

\section{Acknowledgements}

The authors would like to thank Hiromi Kusakabe at National Hospital Organization Kyoto Medical Center for her secretarial assistance and her assistance in acquiring the data. The authors would also like to thank Enago (www.enago.jp) for the English language review.

\section{References}

1. Gharipour M, Mani A, Amini Baghbahadorani M, de Souza Cardoso CK, Jahanfar S, Sarrafzadegan N, et al. How are epigenetic modifications related to cardiovascular disease in older adults? Int J Mol Sci. 2021;22. doi: 10.3390/ijms22189949.

2. Choi KM. Sarcopenia and sarcopenic obesity. Korean J Intern Med. 2016;31:1054-60. doi: 10.3904/kjim.2016.193.

3. Seino S, Shinkai S, lijima K, Obuchi S, Fujiwara Y, Yoshida H, et al. Reference values and age differences in body composition of community-dwelling older Japanese men and women: A pooled analysis of four cohort studies. PLOS ONE. 2015;10:e0131975. doi: 10.1371/journal.pone.0131975.

4. Batsis JA, Villareal DT. Sarcopenic obesity in older adults: aetiology, epidemiology and treatment strategies. Nat Rev Endocrinol. 2018;14:513-37. doi: 10.1038/s41574-018-0062-9.

5. Ponti F, Santoro A, Mercatelli D, Gasperini C, Conte M, Martucci M, et al. Aging and imaging assessment of body composition: from fat to facts. Front Endocrinol. 2019;10:861. doi: 10.3389/fendo.2019.00861.

6. Cruz-Jentoft AJ, Bahat G, Bauer J, Boirie Y, Bruyère O, Cederholm T, et al. Sarcopenia: revised European consensus on definition and diagnosis. Age Ageing. 2019;48:16-31. doi: 10.1093/ageing/afy169.

7. Bastien M, Poirier P, Lemieux I, Després JP. Overview of epidemiology and contribution of obesity to cardiovascular disease. Prog Cardiovasc Dis. 2014;56:369-81. doi: 10.1016/j.pcad.2013.10.016.

8. Britton KA, Massaro JM, Murabito JM, Kreger BE, Hoffmann U, Fox CS. Body fat distribution, incident cardiovascular disease, cancer, and all-cause mortality. J Am Coll Cardiol. 2013;62:921-5. doi: 10.1016/j.jacc.2013.06.027.

9. Hiuge-Shimizu A, Kishida K, Funahashi T, Okutsu M, Kametani R, Kobayashi H, et al.Coexistence of visceral fat and multiple risk factor accumulations is strongly associated with coronary artery disease in Japanese (the VACATION-J study). J Atheroscler Thromb. 2012;19:657-63. doi: 10.5551/jat.13037.

10. Chen LK, Woo J, Assantachai P, Auyeung TW, Chou MY, lijima K, et al.Asian working group for sarcopenia: 2019 consensus update on sarcopenia diagnosis and treatment. J Am Med Dir Assoc. 2020;21:300-7.e2. doi: 10.1016/j.jamda.2019.12.012.

11. Shafiee G, Keshtkar A, Soltani A, Ahadi Z, Larijani B, Heshmat R. Prevalence of sarcopenia in the world: a systematic review and meta- analysis of general population studies. J Diabetes Metab Disord. 2017;16:21. doi: 10.1186/s40200-017-0302-x.

12. Beaudart C, Zaaria M, Pasleau F, Reginster JY, Bruyère O. Health outcomes of sarcopenia: A systematic review and meta-analysis. PLOS ONE. 2017;12:e0169548. doi: 10.1371/journal.pone.0169548.

13. Zhang Y, Hao Q, Ge M, Dong B. Association of sarcopenia and fractures in community-dwelling older adults: a systematic review and meta-analysis of cohort studies. Osteoporos Int. 2018;29:1253-62. doi: 10.1007/s00198-018-4429-5.

14. Yeung SSY, Reijnierse EM, Pham VK, Trappenburg MC, Lim WK, Meskers CGM, et al. Sarcopenia and its association with falls and fractures in older adults: A systematic review and meta-analysis. J Cachexia Sarcopenia Muscle. 2019;10:485-500. doi: 10.1002/jcsm.12411.

15. Uemura K, Doi T, Lee S, Shimada H. Sarcopenia and low serum albumin level synergistically increase the risk of incident disability in older adults. J Am Med Dir Assoc. 2019;20:90-3. doi: 10.1016/j.jamda.2018.06.011. 
16. Zhang H, Lin S, Gao T, Zhong F, Cai J, Sun Y, et al. Association between sarcopenia and metabolic syndrome in middle-aged and older non-obese adults: A systematic review and meta-analysis. Nutrients. 2018;10(3). doi: 10.3390/nu10030364.

17. Chin SO, Rhee SY, Chon S, Hwang YC, Jeong IK, Oh S, et al. Sarcopenia is independently associated with cardiovascular disease in older Korean adults: the Korea National Health and Nutrition Examination Survey (KNHANES) from 2009. PLOS ONE. 2013;8:e60119. doi: 10.1371/journal.pone.0060119.

18. Matsubara Y, Matsumoto T, Inoue K, Matsuda D, Yoshiga R, Yoshiya K, et al. Sarcopenia is a risk factor for cardiovascular events experienced by patients with critical limb ischemia. J Vasc Surg. 2017;65:1390-7. doi: 10.1016/j.jvs.2016.09.030.

19. Liu P, Hao Q, Hai S, Wang H, Cao L, Dong B. Sarcopenia as a predictor of all-cause mortality among community-dwelling older people: A systematic review and meta-analysis. Maturitas. 2017;103:16-22. doi: 10.1016/j.maturitas.2017.04.007.

20. Heber D, Ingles S, Ashley JM, Maxwell MH, Lyons RF, Elashoff RM. Clinical detection of sarcopenic obesity by bioelectrical impedance analysis. Am J Clin Nutr. 1996;64:472S-7S. doi: 10.1093/ajcn/64.3.472S.

21. Baumgartner RN, Wayne SJ, Waters DL, Janssen I, Gallagher D, Morley JE. Sarcopenic obesity predicts instrumental activities of daily living disability in the elderly. Obes Res. 2004;12:1995-2004. doi: 10.1038/oby.2004.250.

22. Rolland Y, Lauwers-Cances V, Cristini C, Abellan van Kan G, Janssen I, Morley JE, et al. Difficulties with physical function associated with obesity, sarcopenia, and sarcopenic-obesity in community-dwelling elderly women: the EPIDOS (EPIDemiologie de l'OSteoporose) Study. Am J Clin Nutr. 2009;89:1895-900. doi: 10.3945/ajcn.2008.26950.

23. Lu CW, Yang KC, Chang HH, Lee LT, Chen CY, Huang KC. Sarcopenic obesity is closely associated with metabolic syndrome. Obes Res Clin Pract. 2013;7:e301-7. doi: 10.1016/j.orcp.2012.02.003.

24. Lee J, Hong YP, Shin HJ, Lee W. Associations of sarcopenia and Sarcopenic obesity with metabolic syndrome considering both muscle mass and muscle strength. J Prev Med Public Health. 2016;49:35-44. doi: 10.3961/jpmph.15.055.

25. Atkins JL, Whincup PH, Morris RW, Lennon LT, Papacosta O, Wannamethee SG. Sarcopenic obesity and risk of cardiovascular disease and mortality: a population-based cohort study of older men. J Am Geriatr Soc. 2014;62:253-60. doi: 10.1111/jgs.12652.

26. Fukuda T, Bouchi R, Takeuchi T, Tsujimoto K, Minami I, Yoshimoto T, et al. Sarcopenic obesity assessed using dual energy X-ray absorptiometry (DXA) can predict cardiovascular disease in patients with type 2 diabetes: a retrospective observational study. Cardiovasc Diabetol. 2018;17:55. doi: 10.1186/s12933-018-0700-5.

27. Evans K, Abdelhafiz D, Abdelhafiz AH. Sarcopenic obesity as a determinant of cardiovascular disease risk in older people: a systematic review. Postgrad Med. 2021:1-12. doi: 10.1080/00325481.2021.1942934.

28. Tian S, Xu Y. Association of sarcopenic obesity with the risk of all-cause mortality: A meta-analysis of prospective cohort studies. Geriatr Gerontol Int. 2016;16:155-66. doi: 10.1111/ggi.12579.

29. Lee DC, Shook RP, Drenowatz C, Blair SN. Physical activity and sarcopenic obesity: definition, assessment, prevalence and mechanism. Future Sci OA. 2016;2:FS0127. doi: 10.4155/fsoa-2016-0028.

30. Donini LM, Busetto L, Bauer JM, Bischoff S, Boirie Y, Cederholm T, et al. Critical appraisal of definitions and diagnostic criteria for sarcopenic obesity based on a systematic review. Clin Nutr. 2020;39:2368-88. doi: 10.1016/j.clnu.2019.11.024.

31. WHO Expert Consultation. Appropriate body-mass index for Asian populations and its implications for policy and intervention strategies. Lancet. 2004;363:157-63. doi: 10.1016/S0140-6736(03)15268-3.

32. Yamada Y, Nishizawa M, Uchiyama T, Kasahara Y, Shindo M, Miyachi M, et al. Developing and validating an age-independent equation using multifrequency bioelectrical impedance analysis for estimation of appendicular skeletal muscle mass and establishing a cutoff for sarcopenia. Int $\mathrm{J}$ Environ Res Public Health. 2017;14(7). doi: 10.3390/ijerph14070809.

33. Cooper R, Hardy R, Bann D, Aihie Sayer A, Ward KA, Adams JE, et al., MRC National Survey of Health and Development Scientific and Data Collection Team. Body mass index from age 15 years onwards and muscle mass, strength, and quality in early old age: findings from the MRC National Survey of Health and Development. J Gerontol A Biol Sci Med Sci. 2014;69:1253-9. doi: 10.1093/gerona/glu039.

34. Murai J, Nishizawa H, Otsuka A, Fukuda S, Tanaka Y, Nagao H, Sakai Y, et al. Low muscle quality in Japanese type 2 diabetic patients with visceral fat accumulation. Cardiovasc Diabetol. 2018;17:112. doi: 10.1186/s12933-018-0755-3.

35. Lees MJ, Wilson OJ, Hind K, Ispoglou T. Muscle quality as a complementary prognostic tool in conjunction with sarcopenia assessment in younger and older individuals. Eur J Appl Physiol. 2019;119:1171-81. doi: 10.1007/s00421-019-04107-8.

36. Umemura S, Arima H, Arima S, Asayama K, Dohi Y, Hirooka Y, et al.The Japanese Society of Hypertension guidelines for the management of hypertension (JSH 2019). Hypertens Res. 2019;42:1235-481. doi: 10.1038/s41440-019-0284-9.

37. Araki E, Goto A, Kondo T, Noda M, Noto H, Origasa H, et al. Japanese clinical practice guideline for diabetes 2019. J Diabetes Investig. 2020;11:1020-76. doi: $10.1111 /$ jdi.13306.

38. Kinoshita M, Yokote K, Arai H, lida M, Ishigaki Y, Ishibashi S, Umemoto S, et al., Committee for Epidemiology and Clinical Management of Atherosclerosis. Japan Atherosclerosis Society (JAS) guidelines for prevention of atherosclerotic cardiovascular Diseases 2017. J Atheroscler Thromb. 2018;25:846-984. doi: 10.5551/jat.GL2017.

39. Sugawara K, Yamashita H, Okumura Y, Yagi K, Yoshimura S, Kawasaki K, et al. Relationships among body composition, muscle strength, and sarcopenia in esophageal squamous cell carcinoma patients. Support Care Cancer. 2020;28:2797-803. doi: 10.1007/s00520-019-05110-7.

40. Lera L, Albala C, Sánchez H, Angel B, Hormazabal MJ, Márquez C, et al. Prevalence of sarcopenia in community-dwelling Chilean elders according to an adapted version of the European working group on sarcopenia in older people (EWGSOP) criteria. J Frailty Aging. 2017;6:12-7. doi:

10.14283/jfa.2016.117.

Page $7 / 12$ 
41. Mosca L, Barrett-Connor E, Wenger NK. Sex/gender differences in cardiovascular disease prevention: what a difference a decade makes. Circulation. 2011;124:2145-54. doi: 10.1161/CIRCULATIONAHA.110.968792.

42. Bosy-Westphal A, Geisler C, Onur S, Korth O, Selberg O, Schrezenmeir J, et al. Value of body fat mass vs anthropometric obesity indices in the assessment of metabolic risk factors. Int J Obes (Lond). 2006;30:475-83. doi: 10.1038/sj.ijo.0803144.

43. Shen W, Punyanitya M, Chen J, Gallagher D, Albu J, Pi-Sunyer X, et al. Waist circumference correlates with metabolic syndrome indicators better than percentage fat. Obesity (Silver Spring). 2006;14:727-36. doi: 10.1038/oby.2006.83.

44. Cao Y, Zhong M, Zhang Y, Zheng Z, Liu Y, Ni X, et al. Presarcopenia is an independent risk factor for carotid atherosclerosis in Chinese population with metabolic syndrome. Diabetes Metab Syndr Obes. 2020;13:81-8. doi: 10.2147/DMSO.S235335.

45. Sasaki H, Kasagi F, Yamada M, Fujita S. Grip strength predicts cause-specific mortality in middle-aged and elderly persons. Am J Med. 2007;120:337-42. doi: 10.1016/j.amjmed.2006.04.018.

46. Leong DP, Teo KK, Rangarajan S, Lopez-Jaramillo P, Avezum A, Jr., Orlandini A, et al., Prospective Urban Rural Epidemiology (PURE) Study investigators. Prognostic value of grip strength: findings from the Prospective Urban Rural Epidemiology (PURE) study. Lancet. 2015;386:266-73. doi: 10.1016/S01406736(14)62000-6.

47. Hamasaki H, Kawashima Y, Katsuyama H, Sako A, Goto A, Yanai H. Association of handgrip strength with hospitalization, cardiovascular events, and mortality in Japanese patients with type 2 diabetes. Sci Rep. 2017;7:7041. doi: 10.1038/s41598-017-07438-8.

48. Poggiogalle E, Lubrano C, Gnessi L, Mariani S, Di Martino M, Catalano C, et al. The decline in muscle strength and muscle quality in relation to metabolic derangements in adult women with obesity. Clin Nutr. 2019;38:2430-5. doi: 10.1016/j.clnu.2019.01.028.

49. Parcha V, Heindl B, Kalra R, Li P, Gower B, Arora G, et al. Insulin resistance and cardiometabolic risk profile among non-diabetic American young adults: insights from NHANES. J Clin Endocrinol Metab. 2021. doi: 10.1210/clinem/dgab645.

50. Adeva-Andany MM, Martínez-Rodríguez J, González-Lucán M, Fernández-Fernández C, Castro-Quintela E. Insulin resistance is a cardiovascular risk factor in humans. Diabetes Metab Syndr. 2019;13:1449-55. doi: 10.1016/j.dsx.2019.02.023.

51. Mesinovic J, McMillan LB, Shore-Lorenti C, De Courten B, Ebeling PR, Scott D. Metabolic syndrome and its associations with components of sarcopenia in overweight and obese older adults. J Clin Med. 2019;8:145. doi: 10.3390/jcm8020145.

52. Reinders I, Murphy RA, Brouwer IA, Visser M, Launer L, Siggeirsdottir K, et al., Age, Gene/Environment Susceptibility (AGES)-Reykjavik Study. Muscle quality and Myosteatosis: novel associations with mortality risk: the age, gene/environment susceptibility (AGES)-Reykjavik study. Am J Epidemiol. 2016;183:53-60. doi: 10.1093/aje/kwv153.

53. Correa-de-Araujo R, Addison O, Miljkovic I, Goodpaster BH, Bergman BC, Clark RV, et al. Myosteatosis in the context of skeletal muscle function deficit: an interdisciplinary workshop at the National Institute on Aging. Front Physiol. 2020;11:963. doi: 10.3389/fphys.2020.00963.

54. Akamatsu Y, Kusakabe T, Arai H, Yamamoto Y, Nakao K, Ikeue K, et al. Phase angle from bioelectrical impedance analysis is a useful indicator of muscle quality. J Cachexia Sarcopenia Muscle. 2021. doi: 10.1002/jcsm.12860.

55. Campins L, Camps M, Riera A, Pleguezuelos E, Yebenes JC, Serra-Prat M. Oral drugs related with muscle wasting and sarcopenia. A review. Pharmacology. 2017;99:1-8. doi: 10.1159/000448247.

56. König M, Spira D, Demuth I, Steinhagen-Thiessen E, Norman K. Polypharmacy as a risk factor for clinically relevant sarcopenia: results from the Berlin aging Study II. J Gerontol A Biol Sci Med Sci. 2017;73:117-22. doi: 10.1093/gerona/glx074.

57. Ishikawa S, Naito S, limori S, Takahashi D, Zeniya M, Sato H, et al. Loop diuretics are associated with greater risk of sarcopenia in patients with nondialysis-dependent chronic kidney disease. PLOS ONE. 2018;13:e0192990. doi: 10.1371/journal.pone.0192990.

\section{Tables}

Table 1 Clinical characteristics of the obese patients 


\begin{tabular}{|c|c|c|c|c|c|c|c|c|c|}
\hline \multirow[b]{2}{*}{ Age (year) } & \multicolumn{3}{|c|}{ All $(n=188)$} & \multicolumn{3}{|c|}{ Male $(n=73)$} & \multicolumn{3}{|c|}{ Female $(n=115)$} \\
\hline & 55.7 & \pm & 15.7 & 54.7 & \pm & 16.7 & 56.4 & \pm & 15.1 \\
\hline BMI $\left(\mathrm{kg} / \mathrm{m}^{2}\right)$ & \multicolumn{3}{|c|}{$31.2(28.1-35.0)$} & \multicolumn{3}{|c|}{$30.6(27.3-34.2)$} & \multicolumn{3}{|c|}{$31.8(28.8-36.3)$} \\
\hline PBF (\%) & 43.0 & \pm & 10.3 & 34.3 & \pm & 7.2 & 48.5 & \pm & 8.0 \\
\hline WC (cm) & \multicolumn{3}{|c|}{$102.0(97.0-111.0)$} & \multicolumn{3}{|c|}{$103.0(98.5-111.0)$} & \multicolumn{3}{|c|}{$102.0(95.0-111.0)$} \\
\hline $\mathrm{SMI}\left(\mathrm{kg} / \mathrm{m}^{2}\right)$ & 8.04 & \pm & 1.16 & 8.94 & \pm & 1.04 & 7.47 & \pm & 0.83 \\
\hline HGS (kg) & 29.9 & \pm & 9.8 & 39.6 & \pm & 7.4 & 23.7 & \pm & 4.9 \\
\hline MQ (kg/kg) & 6.55 & \pm & 1.16 & 6.59 & \pm & 1.12 & 6.52 & \pm & 1.18 \\
\hline $\mathrm{SBP}(\mathrm{mmHg})$ & 136.0 & \pm & 13.6 & 138.0 & \pm & 13.8 & 134.8 & \pm & 13.4 \\
\hline DBP (mmHg) & 82.1 & \pm & 9.5 & 83.3 & \pm & 9.0 & 81.3 & \pm & 9.8 \\
\hline FPG (mg/dl) & 116.2 & \pm & 32.3 & 117.9 & \pm & 28.0 & 115.2 & \pm & 34.8 \\
\hline HbA1c (\%) & 6.4 & \pm & 1.2 & 6.4 & \pm & 1.2 & 6.4 & \pm & 1.3 \\
\hline TG (mg/dL) & 133.4 & \pm & 76.2 & 138.8 & \pm & 83.3 & 129.9 & \pm & 71.4 \\
\hline $\mathrm{HDL}-\mathrm{C}(\mathrm{mg} / \mathrm{dL})$ & 57.5 & \pm & 14.9 & 52.4 & \pm & 11.5 & 60.7 & \pm & 15.9 \\
\hline LDL-C (mg/dL) & 118.8 & \pm & 28.1 & 114.8 & \pm & 23.8 & 121.4 & \pm & 30.4 \\
\hline Current smoker (\%) & \multicolumn{3}{|l|}{8.5} & \multicolumn{3}{|l|}{12.3} & \multicolumn{3}{|l|}{6.1} \\
\hline Hypertension (under treatment) (\%) & \multicolumn{3}{|c|}{$68.1(43.1)$} & \multicolumn{3}{|c|}{$74.0(45.2)$} & \multicolumn{3}{|c|}{$64.3(41.7)$} \\
\hline $\begin{array}{l}\text { Medications for hypertension (n) } \\
\text { (CA/ACEI/ARB/diuretics/ } / \text { /aß/DRI) }\end{array}$ & \multicolumn{3}{|c|}{$68 / 8 / 57 / 19 / 6 / 2 / 1$} & \multicolumn{3}{|c|}{$32 / 4 / 24 / 6 / 4 / 2 / 0$} & \multicolumn{3}{|c|}{$36 / 4 / 33 / 13 / 2 / / 0 / 1$} \\
\hline Diabetes (under treatment) (\%) & \multicolumn{3}{|c|}{$36.7(28.2)$} & \multicolumn{3}{|c|}{$43.8(31.5)$} & \multicolumn{3}{|c|}{$32.2(26.1)$} \\
\hline $\begin{array}{l}\text { Medications for diabetes (n) } \\
\text { (SU/DPP4I/BG/SGLT2I/GLI/aGI/insulin) }\end{array}$ & \multicolumn{3}{|c|}{$22 / 35 / 27 / 21 / 1 / 2 / 8$} & \multicolumn{3}{|c|}{$10 / 14 / 12 / 10 / 1 / 2 / 4$} & \multicolumn{3}{|c|}{$12 / 21 / 15 / 11 / 0 / 0 / 4$} \\
\hline Dyslipidemia (under treatment) (\%) & \multicolumn{3}{|c|}{$70.7(45.7)$} & \multicolumn{3}{|c|}{$74.0(56.2)$} & \multicolumn{3}{|c|}{$68.7(39.1)$} \\
\hline $\begin{array}{l}\text { Medications for dyslipidemia (n) } \\
\text { (statin/fibrate/w3) }\end{array}$ & \multicolumn{3}{|c|}{$67 / 3 / 25$} & \multicolumn{3}{|c|}{$30 / 1 / 14$} & \multicolumn{3}{|c|}{$37 / 2 / 11$} \\
\hline CVD risk score & 1.76 & \pm & 0.89 & 1.92 & \pm & 0.86 & 1.65 & \pm & 0.90 \\
\hline
\end{tabular}

Data are mean $\pm S D$, or median (interquartile range), or frequency percentage.

BMI, body mass index; PBF, percentage body fat; WC, waist circumference; SMI, skeletal muscle mass index; HGS, handgrip strength; MQ, muscle quality; SBP, systolic blood pressure; DBP, diastolic blood pressure; FPG, fasting plasma glucose; HbA1c, hemoglobin A1c; TG, triglyceride; HDL-C: high-density lipoprotein cholesterol; LDL-C: low-density lipoprotein cholesterol; CA, calcium channel antagonist; ACEI, ACE inhibitor; ARB, angiotensin receptor blocker; $\beta$, $\beta$-blockade; aß, aß-blockade; DRI, direct renin inhibitor; SU, sulfonyl urea; DPP4I, dipeptidyl peptidase-4 inhibitor; BG, biguanide; SGLT2I, sodium glucose cotransporter 2 inhibitor; GLI, glinide; aGI, alpha glucosidase inhibitor; CVD: cardiovascular disease.

Table 2 Comparisons of CVD risk scores between the low and high groups in each index 
1. Obesity-evaluated indices

\begin{tabular}{|c|c|c|c|c|c|c|c|c|c|c|c|c|c|c|c|c|c|c|}
\hline \multirow[b]{3}{*}{$\begin{array}{l}\text { Model } \\
1\end{array}$} & \multicolumn{8}{|l|}{ BMI } & \multicolumn{8}{|l|}{ PBF } & \multicolumn{2}{|l|}{ WC } \\
\hline & \multicolumn{4}{|c|}{$\operatorname{Low}(n=93)$} & \multicolumn{4}{|c|}{ High $(n=95)$} & \multicolumn{4}{|c|}{ Low $(n=93)$} & \multicolumn{4}{|c|}{ High $(n=95)$} & \multicolumn{2}{|c|}{ Low $(n=89)$} \\
\hline & 1.73 & $(1.55$ & , & 1.91) & 1.78 & $(1.60$ & , & 1.96) & 1.66 & $(1.48$ & , & 1.84) & 1.85 & $(1.67$ & , & 2.03) & 1.62 & $(1.43$ \\
\hline $\begin{array}{l}\text { Model } \\
2\end{array}$ & 1.73 & $(1.55$ & , & 1.91) & 1.78 & $(1.60$ & , & 1.96) & 1.66 & $(1.48$ & , & 1.84) & 1.85 & (1.67 & , & 2.03) & 1.61 & $(1.43$ \\
\hline $\begin{array}{l}\text { Model } \\
3\end{array}$ & 1.64 & $(1.46$ & , & 1.83) & 1.87 & $(1.68$ & , & 2.05) & 1.62 & $(1.44$ & , & 1.79) & $1.89 *$ & $(1.72$ & , & 2.07) & 1.58 & $(1.40$ \\
\hline \multicolumn{19}{|c|}{ 2. Sarcopenia-evaluated indices } \\
\hline & \multicolumn{8}{|l|}{ SMI } & \multicolumn{7}{|l|}{ HGS } & \multicolumn{3}{|l|}{ MQ } \\
\hline & \multicolumn{4}{|c|}{ Low $(n=93)$} & \multicolumn{4}{|c|}{ High $(n=95)$} & \multicolumn{4}{|c|}{ Low $(n=92)$} & \multicolumn{3}{|c|}{ High $(n=96)$} & \multicolumn{3}{|c|}{ Low (n = 93) } \\
\hline $\begin{array}{l}\text { Model } \\
1\end{array}$ & 1.77 & $(1.59$ & , & 1.96) & 1.74 & $(1.56$ & , & 1.92) & $(1.62$ & , & 1.99) & 1.71 & $(1.53$ & 1.89) & $1.95^{\star \star}$ & , & 2.13) & 1.57 \\
\hline $\begin{array}{l}\text { Model } \\
2\end{array}$ & 1.78 & $(1.59$ & , & 1.96) & 1.74 & $(1.56$ & , & 1.92) & $(1.62$ & , & 1.99) & 1.71 & $(1.53$ & 1.89) & $1.95^{\star \star}$ & , & 2.12) & 1.57 \\
\hline $\begin{array}{l}\text { Model } \\
3\end{array}$ & 1.65 & $(1.46$ & , & 1.85) & 1.86 & $(1.67$ & , & 2.04) & $(1.53$ & , & 1.90) & 1.80 & $(1.61$ & 1.98) & $1.93^{\star *}$ & , & 2.10) & 1.58 \\
\hline
\end{tabular}

Data are estimated mean $(95 \% \mathrm{Cl})$.

BMI, body mass index; PBF, percentage body fat; WC, waist circumference; SMI, skeletal muscle mass index; HGS, handgrip strength; MQ, muscle quality.

Model 1, unadjusted; model 2, adjusted for sex; model 3, adjusted for sex and age.

${ }^{\star} p<0.05,{ }^{* \star} p<0.01$ by ANCOVA between the low group vs. the high group in each obesity- and sarcopenia-evaluated index.

Table 3 Clinical characteristics of the obese patients classified by a combined index of WC and MQ

\begin{tabular}{|c|c|c|c|c|c|c|c|c|c|c|c|c|c|}
\hline \multirow[b]{2}{*}{ Age (year) } & \multicolumn{3}{|c|}{ Group C $(n=54)$} & \multicolumn{3}{|c|}{ Group S ( $\mathrm{n}=35)$} & \multicolumn{3}{|c|}{ Group O $(\mathrm{n}=41)$} & \multicolumn{3}{|c|}{ Group SO $(n=58)$} & \multirow{2}{*}{$\begin{array}{l}p \text { value } \\
0.049\end{array}$} \\
\hline & 55.5 & \pm & 14.5 & 62.1 & \pm & 12.2 & 53.1 & \pm & 16.5 & 53.8 & \pm & 17.4 & \\
\hline Women (\%) & 57.4 & & & 62.9 & & & 65.9 & & & 60.3 & & & 0.859 \\
\hline BMI $\left(\mathrm{kg} / \mathrm{m}^{2}\right)$ & \multicolumn{3}{|c|}{$27.6(26.1-30.3)$} & \multicolumn{3}{|c|}{$28.7(26.9-30.3)$} & \multicolumn{3}{|c|}{$34.5(31.9-39.9)^{\star}+$} & \multicolumn{3}{|c|}{$34.2(32.1-39.9)^{*}+$} & $<0.001$ \\
\hline PBF (\%) & 36.9 & \pm & 8.8 & 38.4 & \pm & 7.0 & 48.4 & \pm & $9.9 *+$ & 47.6 & \pm & $9.5^{\star}+$ & $<0.001$ \\
\hline WC (cm) & \multicolumn{3}{|c|}{$95.0(89.8-99.0)$} & \multicolumn{3}{|c|}{$97.0(92.0-100.0)$} & \multicolumn{3}{|c|}{$111.0(106.3-118.3) \star+$} & \multicolumn{3}{|c|}{$110.5(106.8-121.5) *+$} & $<0.001$ \\
\hline $\mathrm{SMI}\left(\mathrm{kg} / \mathrm{m}^{2}\right)$ & 7.82 & \pm & 1.03 & 7.72 & \pm & 1.13 & 8.22 & \pm & $1.10+$ & 8.32 & \pm & $1.27^{\star *}+$ & 0.029 \\
\hline HGS (kg) & 33.0 & \pm & 9.7 & 25.1 & \pm & $9.6^{*}$ & 32.6 & \pm & $9.1+$ & 27.9 & \pm & $9.0 * \#$ & $<0.001$ \\
\hline MQ (kg/kg) & 7.50 & \pm & 0.71 & 5.49 & \pm & $0.85^{\star}$ & 7.38 & \pm & $0.55 t$ & 5.71 & \pm & $0.72^{\star} \#$ & $<0.001$ \\
\hline $\mathrm{SBP}(\mathrm{mmHg})$ & 132.5 & \pm & 12.5 & 133.7 & \pm & 14.9 & 139.4 & \pm & $14.2^{\star}+$ & 138.3 & \pm & $12.7^{\star}$ & 0.036 \\
\hline $\mathrm{DBP}(\mathrm{mmHg})$ & 83.1 & \pm & 9.8 & 80.2 & \pm & 9.8 & 84.9 & \pm & 7.1 & 80.3 & \pm & 10.2 & 0.063 \\
\hline FPG $(\mathrm{mg} / \mathrm{dL})$ & 108.7 & \pm & 31.3 & 117.9 & \pm & 31.4 & 124.9 & \pm & 31.5 & 126.1 & \pm & 46.4 & 0.061 \\
\hline $\mathrm{HbA} 1 \mathrm{c}(\%)$ & 6.0 & \pm & 0.8 & 6.3 & \pm & 0.8 & 6.6 & \pm & 1.4 & 6.6 & \pm & 1.5 & 0.028 \\
\hline $\mathrm{TG}(\mathrm{mg} / \mathrm{dL})$ & 134.0 & \pm & 96.2 & 126.9 & \pm & 56.0 & 136.3 & \pm & 73.4 & 134.5 & \pm & 68.9 & 0.956 \\
\hline HDL-C (mg/dL) & 59.2 & \pm & 13.9 & 56.8 & \pm & 16.0 & 57.3 & \pm & 13.2 & 56.5 & \pm & 16.4 & 0.794 \\
\hline LDL-C (mg/dL) & 116.7 & \pm & 26.7 & 119.9 & \pm & 28.6 & 123.9 & \pm & 26.7 & 116.4 & \pm & 30.1 & 0.526 \\
\hline Current smoker (\%) & 3.7 & & & 14.3 & & & 12.2 & & & 6.9 & & & 0.260 \\
\hline Hypertension (\%) & 57.4 & & & 68.6 & & & 70.7 & & & 75.9 & & & 0.205 \\
\hline Diabetes (\%) & 16.7 & & & $48.6^{\star}$ & & & $41.5^{\star}$ & & & $44.8^{\star}$ & & & 0.004 \\
\hline Dyslipidemia (\%) & 66.7 & & & 77.1 & & & 65.9 & & & 74.1 & & & 0.589 \\
\hline CVD risk score & 1.41 & \pm & 0.84 & 1.94 & \pm & $0.80 *$ & 1.78 & \pm & 0.91 & 1.95 & \pm & $0.91^{\star \star}$ & 0.005 \\
\hline
\end{tabular}


Data are mean \pm SD or median (interquartile range), or frequency percentage.

BMI, body mass index; PBF, percentage body fat; WC, waist circumference; SMI, skeletal muscle mass index; HGS, handgrip strength; MQ, muscle quality; SBP, systolic blood pressure; DBP, diastolic blood pressure; FPG, fasting plasma glucose; HbA1c, hemoglobin A1c; TG, triglyceride; HDL-C, high-density lipoprotein cholesterol; LDL-C, low-density lipoprotein cholesterol; CVD, cardiovascular disease.

$\S p$ value for difference among the four groups in means (ANOVA followed by Tukey's test), or medians (Kruskal-Wallis test followed by Bonferroni correction), or percentages (Chi-square test).

* $p<0.05$ vs. group $\mathrm{C} ; \uparrow<0.05$ vs. group $\mathrm{S} ; \# p<0.05$ vs. group 0 .

\section{Figures}

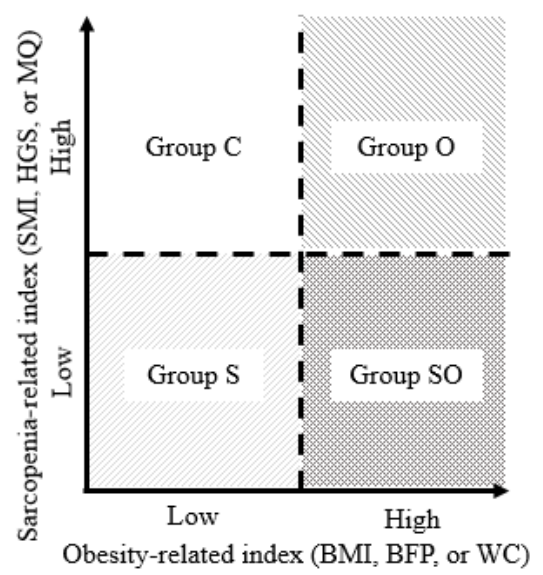

Figure 1

Classification using each obesity- and sarcopenia-evaluated index. Obese patients were classified into four groups, group C, group 0, group S, and group SO, using each obesity- and sarcopenia-evaluated index.

\section{Enrollment \\ $\mathrm{n}=196$ (76 men, 120 women $)$}



Figure 2

Study flow chart of participants 


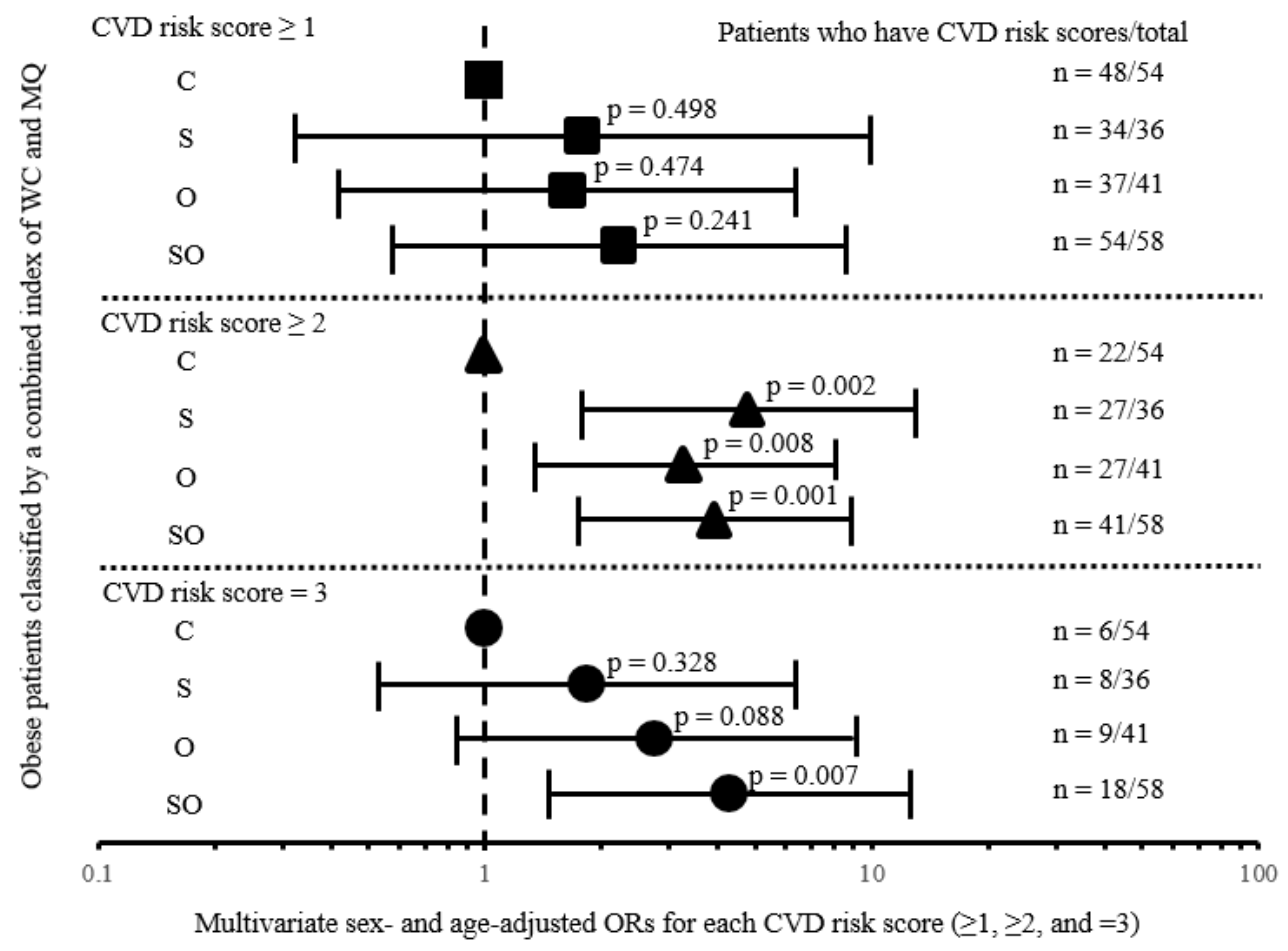

Figure 3

ORs for the CVD risk scores in obese patients of each group Multivariate sex- and age-adjusted ORs in obese patients classified by a combined index of WC and MQ (group C, group S, group O, and group SO). Squares, ORs for CVD risk score $\geq 1$; triangles, ORs for CVD risk score $\geq 2$; circles, ORs for CVD risk score = 3. Solid horizontal lines, $95 \% \mathrm{Cl}$.

\section{Supplementary Files}

This is a list of supplementary files associated with this preprint. Click to download.

- SupplementalTable1.docx 